\title{
A STUDY ON THE VARIATIONS IN THE ORIGIN OF DEEP CIRCU- MFLEX ILIAC ARTERY
}

\section{T. Vasanthakumar ${ }^{1}$, S. Elizabeth priyadarisini ${ }^{2}$.}

${ }^{1}$ Professor and HOD of Anatomy, Stanley Medical College,Chennai, Tamilnadu, India.

${ }^{* 2}$ Assistant Professor of Anatomy, Stanley M edical College, Chennai, Tamilnadu, India.

\section{ABSTRACT}

Background: The deep circumflexiliac artery(DCIA) is a lateral branch of external iliac artery(EIA) arising posterior to the inguinal ligament(IL).DCIA flaps are used extensively in oromandibular reconstruction. This study focusses on the normal and anatomical variations in the origin of the deep circumflex iliac artery.

Material and Methods: Fifty adult lower limb specimens were obtained from the embalmed cadavers at the department of Anatomy, Stanley Medical College,Chennai.The inguinal regions and the corresponding femoral triangles were dissected.The origin of the DCIA in relation to the inguinal ligament was noted.Variations present in the origin of DCIA was identified and studied.

Results: Out of the 50 lower limb specimens, in 32 cases(64\%) the DCIA arose laterally from the EIA posterior to the inguinal ligament.In 14 cases(28\%) the deep circumflex iliac artery took origin from the femoral artery(FA) below the IL.In 4 specimens(8\%) it arose from the EIA above the IL.

Conclusion: There are variations present in the origin of theDCIA.The DCIA flaps are used in mandibular reconstruction procedures and their dissection needs a good anatomical knowledge of the normal and variant origins of the deep circumflex iliac artery

KEY WORDS: Deep circumflex iliac artery,External iliac artery, Inguinal ligament,femoral artery.

Address for Correspondence: Dr.S.Elizabeth priyadarisini, Assistant Professor of Anatomy, Stanley Medical College, Chennai, Tamilnadu, India. E-Mail: drelizabethmmc@gmail.com

\begin{tabular}{|l|l|}
\hline \multicolumn{3}{|c|}{ Access this Article online } \\
\hline Quick Response code & Web site: International Journal of Anatomy and Research \\
ISSN 2321-4287 \\
www.ijmhr.org/ijar.htm
\end{tabular}

\section{INTRODUCTION}

The deep circumflex iliac artery branches laterally from the external iliac artery posterior to the ingunal ligament almost opposite the origin of the inferior epigastric artery.It ascends towards the anterior superior iliac spine behind the IL,It pierces the transversalis fascia, skirts the internal lip of the iliac crest and running between the transversusabdominis and the internal oblique muscle anastomoses with the ilioilumbar and the superior gluteal arteries [1]. The DCIA flaps are used extensively in oromandibular reconstruction surgeries.The DCIA has been demonstrated as a reliable and consistent pedicle for carrying the groin skin and iliac bone as an osteomyocutaneous flap [2,3]. The DCIA flaps were even designed with a perforator based skin paddle [4]. The DCIA flaps are a useful option for repair of mandibular defects because it offers large amount of bone complex for reconstruction in the dentate mandible [5]. It also provides a large segment of vascularised bone, an inconspicuous donor scar and low donor site morbidity [6,7]. The DCIA perforator flaps without iliac crest bone are also used for reconstruction of cutaneous defects [8]. 


\section{MATERIALS AND METHODS}

Fifty adult lower limb specimens were obtained from the embalmed cadavers at the department of Anatomy, Stanley Medical College, Chennai, India.

The inguinal regions were dissected and the inguinal ligament was exposed.The corresponding femoral triangles were also dissected and the branches of the femoral artery in the upper femoral triangle identified and any unusual branches of the femoral artery noted.The origin of the DCIA from the external iliac artery and its course was carefully dissected and studied. Variations in the DCIA origin like high or low origin was identified,studied and photographed.

\section{RESULTS}

Out of 50 lower limb specimens in 32 cases(64\%) the deep circumflex iliac artery arose from the EIA at the level of the inguinal ligament. In about 14 cases(28\%) the DCIA arose from the femoral artery below the level of the IL.In 4 specimens (8\%)the DCIA took origin from the external iliac artery above the level of IL.

Fig. 1: Deep circumflex iliac artery arising at the level of inguinal ligament. IL partially lifted up.

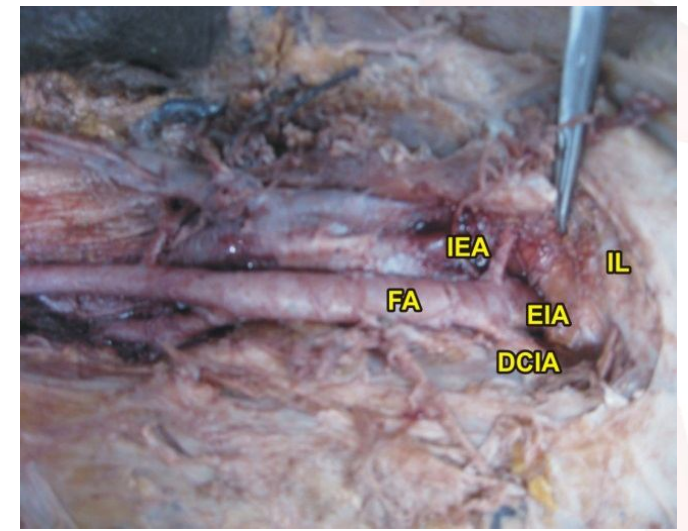

Fig. 2: Deep circumflex iliac artery arising at the level of inguinal ligament.

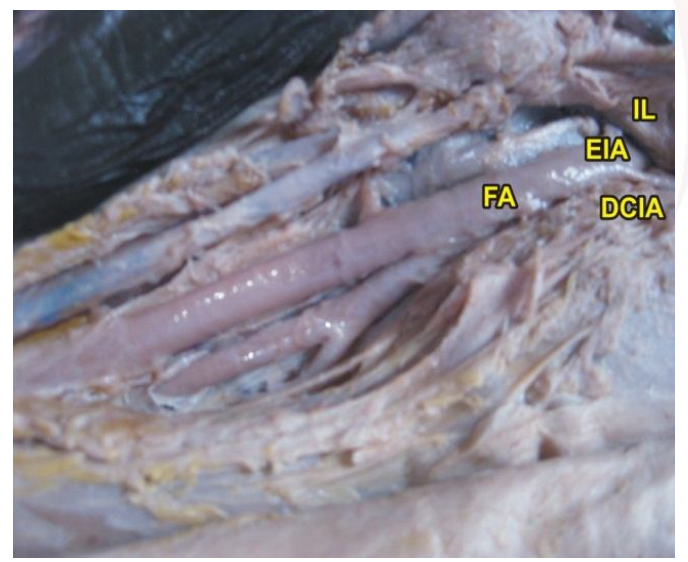

Fig. 3: Deep circumflex iliac artery arising below the inguinal ligament from the femoral artery.

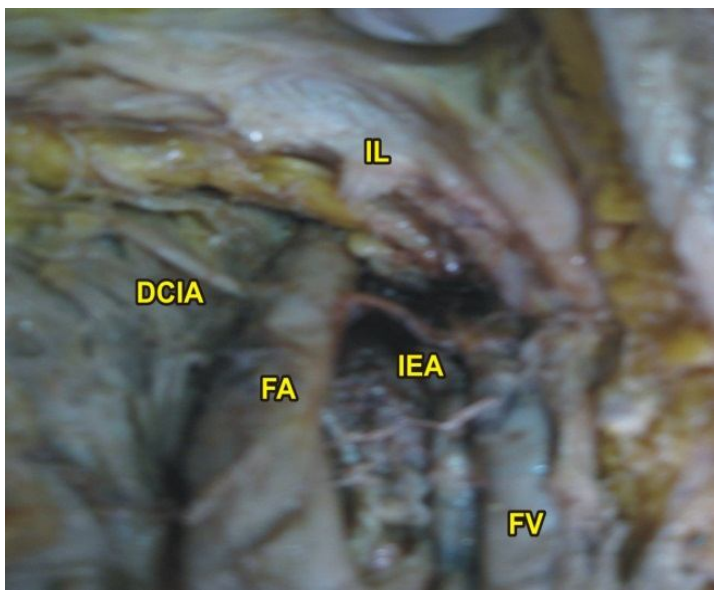

Fig. 4: Inguinal ligament lifted up to show the origin of the deep circumflex iliac artery above the level of inguinal ligament from the external iliac artery.

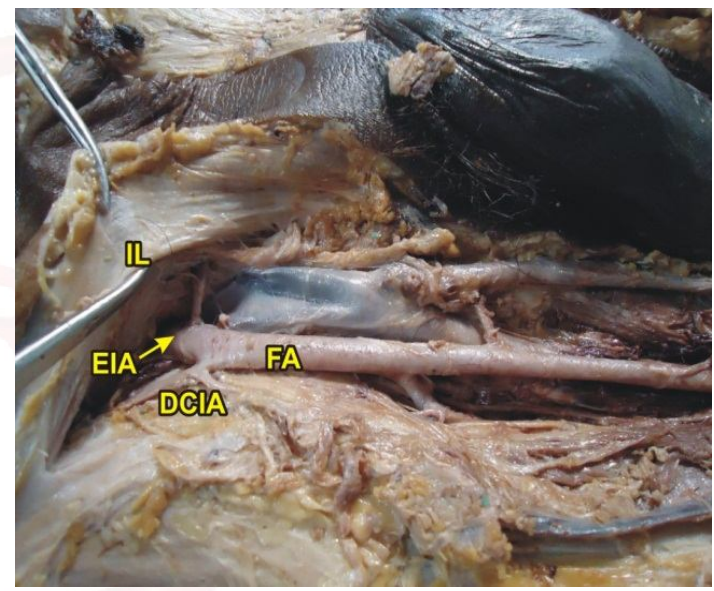

\section{DISCUSSION}

In the present study the DCIA arose from the EIA at the level of IL in 32 cases(64\%), it originated from the femoral artery below the inguinal ligament in 14 specimens(28\%) and it took origin from the external iliac artery above the IL in 4 cases(8\%). In a study by Ogami et al [9] the $\mathrm{DCIA}$ ran parallel to the IL from the femoral artery or the external iliac artery.Out of 100 cadavers at least one superficial circumflex iliac artery and onedeep circumflex iliac artery was found around each femoral triangle. $58 \%$ of DCIA originated from the FA and the rest from the EIA. In Emura et al study [10] in one case the DCIA and the medial circumflex femoral artery arose as a common trunk from the lateral side of the femoral artery and turned medially behind the FA. In Sasaki K et al study [11] two variations in the branching pattern of DCIA was noted. In the first case the deep circumflex iliac artery was absent and in the second case the ascending branch of the DCIA had a separate take off 
T. Vasanthakumar, S. Elizabeth priyadarisini. A STUDY ON THE VARIATIONS IN THE ORIGIN OF DEEP CIRCUMFLEX ILIAC ARTERY.

directly from the EIA.

Very few studies have been reported in the $V$ literature regarding the variations in the DCIA origin. Satheesha Nayaket al [12] reported a case with bilateral low origin of DCIA and inferior epigastric artery from the femoral artery.

\section{CONCLUSION}

DCIA flaps has several advantages in reconstruction of oromandibular defects.Due to its variant vessel antomy,the dissection of DCIA flaps are time consuming and warrants a accurate anatomical knowledge compared with commonly harvested free flaps. This study on the variant origins of the DCIA will be useful to the surgeons while planning procedures around the inguinal region.

\section{ABBREVIATIONS}

EIA - External lliac Artery

FA - Femoral Artery

IL - Inguinal ligament

DCIA - Deep Circumflex lliac Artery

IEA - Inferior Epigastric Artery

FV - Femoral Vein

\section{Conflicts of Interests: None}

\section{REFERENCES}

[1]. Susan standring [2008] Grays anatomy, 40 th edition, Churchill Livingstone Elsevier,pg.

[2]. Taylor GI, Townsend P, Corlett R. Superiority of the $\mathrm{DCl}$ vessels as the supply for free groin flaps: ClinicalWork; Plastic reconstrsurg 1979;64:745.
[3]. Taylor GI, Townsend P, Corlett R. Superiority of the $\mathrm{DCl}$ vessels as the supply for free groin flaps: Experimental Work 1979;64:595.

[4]. SafakT, Klebuc MJ, M avili E et al. A new design of the iliac crest microsurgical free flap without including the obligatory muscle cuff. Plastreconstsurg 1997;100:1703.

[5]. Brown JS. DCIA free flap with 10 mucle as a new method of immediate reconstruction of maxillectomydefect:Head and Neck 1996;18(5):412421.

[6]. Kudoklnjioka Y. Review of bone grafting for reconstruction of discontinuity defects of the mandible, J Oral Surg. 1978;36(10):791-793.

[7]. Bitter K, Schlesinger Westerman U. The iliac bone or osteocutaneous transplant pedicled to the DCIA. J Maxillofac Surg 1983;11:241-247.

[8]. Akyurek, M ustafa MD, Conejero Alejandro MD, Dunn, Raymond MD. DCIA perf flap without iliac crest. Plastreconstsurg Dec 2008;122(6):1790-1795.

[9]. OgamiK, Murata H, Sakai A, Sato S, Saiki K, Okamoto K. Deep and superficial iliac arteries and their relation to the ultrasound guided femoral nerve procedure-A Cadaver study. Clin Anat. 2017;30(3):413420.

[10]. Emura S, Shoumura S, Ishizaki N, YamahiraT. The anatomical study on the branches of the femoral artery-Comparison with the findings of Adachi's classification. Kaibogaku Zasshi 1989 Jun;64(3):196-205.

[11]. Sasaki K, Nozaki M, Okagaki M, Nishikage M , Kikuchi Y. Variations in the DCIA: Clinical consideration in raising iliac osteocutaneous free flaps", JReconstrM icrosurg 1999 Oct;15(7):527-530.

[12]. Satheesha Nayak B, Snigdha Mishra M, Bincy M Georgi, Saju Binu Cherian, Surekha D Shetty. Unusual branches of femoral artery in the femoral triangle-A case report. Int J M orphol 2013;31(3):819821.

\section{How to cite this article:}

T. Vasanthakumar, S. Elizabeth priyadarisini A STUDY ON THE VARIATIONS IN THE ORIGIN OF DEEP CIRCUMFLEX ILIAC ARTERY. Int J Anat Res 2017;5(4.1):4451-4453. DOI: 10.16965/ ijar.2017.367 